\section{Letrōnica}

http://revistaseletronicas pucrs br/ois/index php/letronica/

doi" http://dx.doi.org/10.15448/1984-4301.2018.s.31337

\title{
A História da literatura ocidental de O. M. Carpeaux e a crítica de Wilson Martins
}

\section{Wilson Martins' criticism to History of Western Literature by O.M. Carpeaux}

Professor de Língua e Literatura Alemã, Língua e

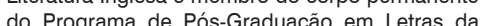
PUCRS. É um dos editores de Letrônica e dos responsáveis pela organização do presente número.

(1) hittps://orcid.org/0000-0002-6920-2669 E-mail: perth@pucrs.br
RESUMO: A primeira publicação da História da Literatura Ocidental, de Otto Maria Carpeaux, está prestes a completar sessenta anos. Obra singular no contexto do ensaísmo literário brasileiro, o livro foi poucas vezes examinado criticamente. 0 que se promove no presente artigo é uma revisão das resenhas publicadas pelo eminente crítico Wilson Martins à época do aparecimento da obra, do final dos anos de 1950 ao início dos anos de 1960. Além de reconhecer a contribuição de Carpeaux ao conhecimento das literaturas estrangeiras, o crítico dedicou especial atenção aos critérios historiográficos de inclusão, ao cânone e à periodização.

Palavras-chave: Historiografia literária; Inclusão; periodização; Otto Maria Carpeaux; Wilson Martins.

ABSTRACT: The first edition of Otto Maria Carpeaux' História da Literatura Ocidental (A History of Western Literature) occurred almost sixty years ago. A singular work in the context of Brazilian literary essayism, the book has found practically no critical reviewers. The present article examines the reviews published by eminent Brazilian critic Wilson Martins at the time of the work's first appearance from the end of the 1950s to the early 1960s. Besides recognizing Carpeaux' contribution to the knowledge of foreign literatures, the critic dedicated special attention to the criteria of literary history writing, like inclusion, canon and periodization.

Keywords: Literary history writing; inclusion; Periodization; Otto Maria Carpeaux; Wilson Martins. 
$\mathrm{H}$ istórias da literatura universal costumam ocupar nas bibliotecas uma posição semelhante à dos dicionários e dos demais livros de referência. São em geral obras bastante volumosas, que compulsamos de vez em quando, se queremos informação sobre a literatura de outros países, mas quase nunca se queremos saber algo sobre a nossa. Aparentemente raros são os que leem tais obras por inteiro, e ainda mais raros os que lhes dedicam estudos críticos. 0 presente artigo ocupa-se, nesse sentido, de um caso excepcional: trata-se da História da literatura ocidental, de Otto Maria Carpeaux, e das críticas que lhe foram dirigidas por Wilson Martins. Editada pela primeira vez entre 1959 e 1966, as reedições que a obra teve no início do terceiro milênio parecem justificar o exame a que aqui se procede. Antes de entrar no assunto da crítica propriamente dita, seguem-se algumas palavras a respeito da evolução do gênero história da literatura universal e também da gênese da história em questão ${ }^{1}$.

Obras que tentam reunir as grandes realizações da arte da escrita existem há pelo menos mil e quinhentos anos. De início, nessas obras, o que hoje designamos por conhecimento literário vinha acompanhado de tudo o mais que se julgava apropriado à formação religiosa e profana de uma pessoa. Um exemplo desse tipo são as Institutiones, de Cassiodoro. Contudo, já no século IV d.C., São Jerônimo distinguia entre litteratura, o conjunto dos escritos pagãos da Antigüidade, e scriptura, o dos escritos cristãos. Representações panorâmicas de assuntos literários começaram a aparecer durante o Renascimento. As expressões "história literária" e "história da literatura" estão documentadas desde o século XVIII, na França e na Espanha, sendo que as bases teóricas da história literária, como se sabe, foram desenvolvidas no final desse mesmo século, na Alemanha. A

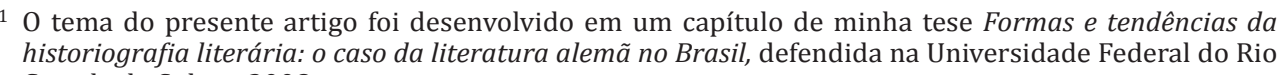
Grande do Sul em 2008. expressão "literatura universal", no entanto, só surgiria no século XIX e se deve a Johann Wolfgang von Goethe. No dia 31 de janeiro de 1827, este disse a seu secretário Johann Peter Eckermann:

Entendo cada vez mais que a literatura constitui um bem comum da humanidade, que se manifesta em centenas e centenas de pessoas em toda parte e em todos os tempos [...]. No momento, falar em literatura nacional não significa muito, pois chegou a época da literatura universal, e cada qual deve agora atuar no sentido de apressar a vinda dessa época (ECKERMANN, 1958)2.

Por não definir com precisão o que entendia por literatura universal ou mundial - Weltliteratur admite ambas as traduções -, a afirmação de Goethe foi entendida das mais diversas maneiras. Mas, embora não se lhe possa atribuir a fundação do gênero conhecido como história da literatura universal, cuja origem, como se viu, é antiga, o poeta alemão certamente lhe deu um impulso significativo. Quando ideias nacionalistas jogavam os povos europeus uns contra os outros na segunda metade do século XIX, as histórias da literatura universal preenchiam uma das funções da recém-fundada disciplina da Literatura Comparada, que era a de facilitar o conhecimento recíproco das nações separadas pelos conflitos. Embora até hoje projetos de grandes histórias da literatura universal não tenham desaparecido de todo, lançamentos desse gênero são, no entanto, raros. As visões da totalidade perderam a atração que possuíam, pois já não se acredita nas suas possibilidades harmonizadoras, privilegiando-se a visão especializada e os estudos fragmentados.

Uma pesquisa, mesmo que rápida, em algumas grandes bibliotecas revela que no Brasil da primeira metade do século XX as histórias da literatura universal em outras línguas (especialmente em espanhol) eram numerosas. As traduções apresentam-se em menor número, sendo

${ }^{2}$ A tradução é do autor do presente artigo. 
de destacar-se a tradução da História da literatura mundial, do norteamericano John Macy, realizada por Monteiro Lobato para a Companhia Editora Nacional, presumivelmente em 1936 (MACY, 1941). Por outro lado, autores brasileiros também se aventuraram por essa seara, como Manuel Bandeira, quando professor na Universidade do Brasil (BANDEIRA, 1960); Estêvão Cruz (CRUZ, 1936) e José Mesquita de Carvalho (CARVALHO, 1940), que escreveram para a Editora Globo, de Porto Alegre; e G. D. Leoni, da PUC de São Paulo (LEONI, 1949). Essas obras surgiram principalmente a partir da década de 1930 e, quando não se destinavam ao uso das escolas normais, isto é, das escolas secundárias voltadas à formação de professores, serviam para abastecer de material didático os alunos das faculdades de filosofia, ciências e letras, que então se criavam. O grau de abrangência dessas histórias é variado, dependendo, aparentemente, do leitor ou estudante que constituía seu escopo.

Embora nunca tivesse sido professor, Otto Maria Carpeaux, na opinião de muitos, produziu a melhor das histórias da literatura ocidental. Nascido em Viena em 1900, Carpeaux fugiu da Europa em conseqüência do nazismo, chegando ao Brasil em 1939. Superadas as dificuldades iniciais do imigrante, começou a exercer aqui a maturidade intelectual plena em que então, aos 39 anos de idade, se encontrava. Recomendado por Álvaro Lins, estabeleceuse na imprensa carioca, escrevendo ensaios para o Correio da Manhã e os Diários Associados. De 1942 a 1944, foi diretor da biblioteca da Faculdade Nacional de Filosofia da Universidade do Brasil, e de 1944 a 1945, diretor da biblioteca da Fundação Getúlio Vargas.

A História da literatura ocidental foi escrita em um espaço de aproximadamente dois anos, no período em que Carpeaux exerceu a função de bibliotecário, e revista cerca de 10 anos depois, sendo publicada pela primeira vez em oito volumes, pelas Edições O Cruzeiro, entre 1959 e 1966 (CARPEAUX, 1959-1966). A segunda edição, corrigida, sairia pela Editora
Alhambra, entre 1978, ano da morte de Carpeaux, e 1982 (CARPEAUX, 1978-1982). Uma terceira edição, anunciada desde 1999 pelas editoras Topbooks e UniverCidade, do Rio de Janeiro, parece não haver se concretizado $^{3}$. Ao invés disso, quando a obra de Carpeaux caiu em domínio público, apareceram duas edições em grande formato - uma do Senado Federal (2008) e outra da editora Leya Livros e Livraria Cultura (2011) -, bem como uma edição de bolso da editora Leya (2014). Embora o título restringisse seu escopo, obrigando-o tão-somente a tratar da literatura da Europa e das Américas, com exclusão, portanto, das literaturas orientais, como a chinesa, a indiana, a egípcia, a fenícia e a hebraica, Carpeaux considera devidamente esta última quando trata da Bíblia. A consciência de que fazia história da literatura universal também se manifesta no sétimo volume, quando, ao encerrar a parte narrativa de sua história, Carpeaux discute a conversação de Goethe com Eckermann acima referida.

A crítica à História da literatura ocidental foi, desde o início, muito favorável, por vezes entusiástica, e talvez mesmo exagerada. Terão, porventura, contribuído para tal a credibilidade conquistada por Carpeaux com seu currículo europeu (era doutor em Ciências Naturais pela Universidade de Viena), a rapidez com que se tornara proficiente em português (seus primeiros artigos, escritos em francês, eram traduzidos para o português na redação do jornal, recurso que em breve se tornou desnecessário), a vasta cultura que ostentava em seus artigos (dos quais já haviam sido publicadas várias coletâneas: A cinza do purgatório, 1942, Origens e fins, 1943, Respostas e perguntas, 1953, e Presenças, 1958), seus estudos de literatura brasileira (que haviam resultado na utilíssima Pequena bibliografia crítica da literatura brasileira, 1949), e seu conhecimento de outros domínios da arte (revelado, por exemplo, em Uma nova história

${ }^{3}$ As afirmações sobre um projeto editorial de reedição da obra de Carpeaux, incluindo História da Literatura Ocidental, encontram-se em: Carpeaux, Ensaios reunidos I, 1999. 
da música, 1958). De fato, referências elogiosas à História da literatura ocidental encontram-se em numerosos lugares. Para uma referência mais imediata, vejam-se, por exemplo, uma bem fundamentada apreciação de Antonio Candido, em "Dialética apaixonada"4; as palavras de Alfredo Bosi, em História concisa da literatura brasileira ${ }^{5}$; e as páginas polêmicas e entusiásticas de Olavo de Carvalho, na introdução aos Ensaios reunidos: 1942-1978, de Carpeaux ${ }^{6}$.

Wilson Martins (São Paulo, 1921 - Curitiba, 2010) pertenceu a uma geração vinte anos mais jovem que a de Otto Maria Carpeaux e certamente lera tudo o que este havia escrito, como atestam as repetidas citações em cada um dos quatorze volumes de Pontos de vista, a coletânea das críticas que publicou de 1954 a 1974 em O Estado de São Paulo, e a partir de 1978 no Jornal do Brasil. A maioria absoluta dessas dezenas de citações destina-se a apoiar teses próprias ou a ilustrá-las com afirmações de Carpeaux. Martins não via Carpeaux como crítico literário e sim como ensaísta, ou seja, um escritor que funda suas opiniões em perspectivas intelectuais e não em juízos de valor:

A "forma de espírito" de Otto Maria Carpeaux concilia-se mais com o ensaio de erudição literária, com a historiografia fartamente interpretativa e de amplos horizontes, do que com a crítica literária propriamente dita, presa ao cotidiano e ao imediato, menos dependente da cultura e do ecumenismo intelectual que da intuição e do gosto. Bem entendido, são distinções que faço a título didático, já que todas essas condições da inteligência não se excluem mas se completam, ou antes, se "complementam" no plano teórico, embora nem sempre se enriqueçam no plano prático (MARTINS, 1991-2001, v. 4, p. 398).

Para Martins, Otto Maria Carpeaux pertencia à categoria do "humanista das letras, o grande 'amador', no sentido nobre da palavra” (id., ibid., p. 399).

\footnotetext{
4 Leia Livros v. 2, n. 3, 1979, reproduzida em: A. Candido, Recortes, 1993, p. 89-95.

5 A. Bosi, 1988, p. 552s.
}

6 O. de Carvalho, 1999, p. 15-70.
"Escritor de escritores, leitura de profissionais - mais que escritor para o público e leitura de amadores da literatura” (id., ibid., p. 403).

Artigos específicos de Wilson Martins sobre cada um dos seis primeiros volumes da História da literatura ocidental foram publicados logo após o respectivo lançamento. Também aqui as referências a Carpeaux, embora frequentemente discordantes, são sempre justas, havendo um equilíbrio entre a crítica e o elogio.

Wilson Martins começa por reconhecer a qualificação do autor para o empreendimento de escrever uma história da literatura ocidental: Otto Maria Carpeaux é "o único em condições de realizar esse trabalho, pois, sendo brasileiro, não deixou de ser europeu, vive conscientemente a condição de 'cidadão da Europa'” (id., ibid., v. 3, p. 507s.). Martins reconhece as dificuldades da empresa: o ordenamento da matéria imensa, a exposição do assunto - a visão do historiador -, a seleção dos autores; aplaude as soluções encontradas por Otto Maria Carpeaux para os dois primeiros problemas, critica seu tratamento dos autores individuais:

Uma história dessa natureza é, em grande parte, uma história dos "universais", nos dois sentidos da palavra. Cabe admitir, apenas e rigorosamente, os escritores que tiveram uma repercussão e uma influência internacionais, em pelo menos dois dos países do Ocidente [...] e aqueles cuja obra marcou um estilo, um período, além de ser marcada por eles. Otto Maria Carpeaux, selecionando 8.000 autores, deixouse dominar mais pelo espírito de erudição do que pelo espírito crítico. Neste primeiro volume, são dezenas os nomes de escritores que, tendo um lugar privilegiado nas suas respectivas literaturas, não respondem às condições de dupla universalidade a que aludi: há páginas e páginas desta História que lembram as velhas histórias da literatura brasileira com a sua fastidiosa, inútil e injustificada enumeração de oradores sacros e poetas menores (id., ibid., v. 3, p. 509).

Essa crítica aos padrões de seleção repete-se em relação aos demais volumes, chegando Wilson Martins a afirmar: "Em muitos casos, o Ocidente de Otto Maria Carpeaux é puramente geográfico; em outros, é inglês, ho- 
landês, francês, etc., sem chegar a ser 'ocidental', sem transpor os limites em que a nacionalidade se transforma em universalidade" (id., ibid., v. 4, p. 307. Cf. tb. id., ibid., v. 5, p. 16; v. 6, p. 80). A literatura ocidental constitui-se, para Martins, a partir da Revolução Francesa. Antes disso, “[...] havia as várias literaturas do Ocidente, o que é completamente diverso" (id., ibid., v. 5, p. 145).

Quanto à periodologia, Carpeaux tenta anular os conceitos de Idade Média e Renascença, pois, para um católico, como ele, não houve uma "idade das trevas", e a literatura renascentista já existia antes do período assim denominado, formando, portanto, uma continuidade entre a literatura antiga e a moderna. A contradição é que, ao mesmo tempo em que os rejeita, Carpeaux utiliza aqueles conceitos para classificar a produção literária, o que, segundo Wilson Martins, constitui o problema fundamental do primeiro volume (cf. id., ibid., v. 3, p. 511s.). Da mesma forma, Carpeaux tenta, várias vezes, contrariar, "nem sempre justificadamente", as hierarquias estabelecidas pelo considerado clássico em literatura. Um exemplo é sua tentativa de relativizar a importância do Classicismo francês do século XVII (cf. id., ibid., v. 4, p. 308).

Erros cronológicos também são apontados. Assim, por exemplo, quando Carpeaux estuda Rabelais antes de Montaigne, produz um anacronismo de consequências para a avaliação desses autores (cf. id., ibid., v. 3, p. 511). Além disso, segundo Martins, Carpeaux apresenta lacunas na informação e na bibliografia a respeito de vários autores, como Pascal e Mme de Sévigné. O catolicismo de Carpeaux também é responsabilizado por seu jesuitismo e jansenismo, ou seja, pelo rigorismo moral que se evidencia na seleção bibliográfica, levando-o a preferir as edições expurgadas às que apresentam o texto integral em casos como o de Casanova. Problemas conceituais encontrar-se-iam na utilização de certos termos da Literatura Comparada, como, por exemplo, "imitação" e "influência": "Otto Maria Carpeaux parece extrapolar da 'imitação' para a 'influência', assim como não distingue suficientemente as diferenças essenciais entre as duas 'ondas da invasão espanhola"' (id., ibid., v. 4, p. 310).

Além desses, inúmeros outros pequenos reparos são feitos pelo crítico à História da literatura ocidental, estendendo-se dos conceitos aos fatos históricos e às falhas editoriais. Entretanto, mais de uma vez, Wilson Martins tempera suas próprias críticas com observações relativizantes. Sirva de exemplo esta, sobre o sexto volume:

Claro está, uma crítica minuciosa deste livro exigiria não apenas outro livro, mas, ainda, uma équipe de críticos. É certo que, nas perspectivas grandiosas da literatura ocidental, pouco importam pequenos erros de apreciação a respeito de tal poeta menor do Piemonte ou de um romancista do Tirol; como nos grandes cálculos matemáticos, há uma tolerância compreensível para as dezenas incorretas. É possível, por consequência, que os especialistas em tal ou tal das literaturas do Ocidente encontrem do que discordar; parece inegável, entretanto, que as linhas de conjunto estão exatas, ainda que um espírito seletivo mais rigoroso pudesse ter feito com que sobressaíssem em sua legítima grandeza os escritores realmente incomparáveis (id., ibid., v. 6, p. 81).

Levando em consideração alguns princípios gerais de historiografia literária, como bases de representação, periodologia, cânone e perspectiva, as crenças e os preceitos críticos de Wilson Martins para o gênero poderiam ser assim reexpressos: a literatura é um fenômeno típico do Ocidente; a representação histórico-literária deve levar em consideração fatores estéticos e sociais; grandes autores e grandes obras encontram-se em várias latitudes, porém a história da literatura ocidental deve acolher apenas aqueles que tiveram repercussão além das fronteiras nacionais; a adoção da periodologia convencional e aceita contribui para a clareza da exposição; a aceitação do clássico constitui um caminho seguro, que ajuda a evitar as arbitrariedades; o cânone da literatura universal ignora os autores e obras que tiveram importância apenas local ou nacional; a perspectiva pessoal, 
filosófica, religiosa, influi sempre nas decisões tomadas em relação aos princípios de representação, periodização e cânone.

Pode-se afirmar que, assim como na literatura, esse último e inevitável aspecto torna visíveis também na historiografia literária as marcas do indivíduo. Nesse sentido, Otto Maria Carpeaux encontrou em Wilson Martins um leitor competente e justo, que partilha com ele várias crenças e lhe aponta as falhas e incoerências. É ainda um leitor que crê na possibilidade das grandes sínteses, e que se situa, na perspectiva de hoje, em um momento anterior à visão fragmentada que se encontra, por exemplo, nas várias obras nacionais e estrangeiras em que a discussão do cânone substitui a historiografia no sentido tradicional.

\section{Referências}

BANDEIRA, Manuel. Noções de história das literaturas. 5. ed. Rio de Janeiro: Fundo de Cultura, 1960. 2 v.

BOSI, Alfredo. História concisa da literatura brasileira. São Paulo: Cultrix, 1988.

CANDIDO, Antonio. Dialética apaixonada. In: BOSI, Alfredo. Recortes. São Paulo: Companhia das Letras, 1993. p. 89-95.

CARPEAUX, Otto Maria. História da literatura ocidental. Rio de Janeiro: O Cruzeiro, 19591966. $8 \mathrm{v}$.

CARPEAUX, Otto Maria. História da literatura ocidental. 2. ed., rev., atualiz. Rio de Janeiro: Alhambra, 1978-1982. $8 \mathrm{v}$.

CARPEAUX, Otto Maria. História da literatura ocidental. 3. ed. Brasília: Senado Federal, 2008. $4 \mathrm{v}$.

CARPEAUX, Otto Maria. História da literatura ocidental. 4. ed. São Paulo: Leya Livros; Livraria Cultura, 2011. 4 v.

CARPEAUX, Otto Maria. História da literatura ocidental. 5. ed. Edição de bolso. São Paulo: Leya Livros; Livraria Cultura, 2014. 10 v.

CARPEAUX, Otto Maria. Ensaios reunidos I. Rio de Janeiro: UniverCidade Topbooks, 1999.
CARPEAUX, Otto Maria. Ensaios reunidos II. Rio de Janeiro: UniverCidade Topbooks, 2005.

CARVALHO, José Mesquita de. História da literatura mundial. Porto Alegre: Globo, 1940. CARVALHO, Olavo de. Introdução a um exame de consciência. In: CARPEAUX, Otto Maria. Ensaios reunidos: 1942-1978. Rio de Janeiro: UniverCidade; Topbooks, 1999. v. 1. p. 15-70.

CRUZ, Estêvão. História universal da literatura. Porto Alegre: Globo, 1936. 2 v.

ECKERMANN, Johann Peter. Gespräche mit Goethe in den letzten Jahren seines Lebens. Berlin: Deutsche Buch-Gemeinschaft, 1958.

LEONI, G. D. Literatura universal: esboço geral de uma história comparada das literaturas. São Paulo: Sonora, 1949. [Rio de Janeiro: Ouro, 1966.]

MACY, John. História da literatura mundial. Trad. Monteiro Lobato. 2. ed. São Paulo: Nacional, 1941. [5. ed. rev. por Lula Margarido, 1967].

MARTINS, Wilson. Pontos de vista: crítica literária. São Paulo: T. A. Queiroz, 1991-2001. v. 1-14.

THEOBALD, Pedro. Formas e tendências da historiografia literária: o caso da literatura alemã no Brasil. Tese (Doutorado) - Universidade Federal do Rio Grande do Sul, Porto Alegre. 2008.

Recebido em 03/02/2018. Aceito em 10/05/2018. 
